\title{
Music Therapy Programming for Persons With Eating Disorders:
}

\section{A Review With Clinical Examples}

\author{
Varvara Pasiali ${ }^{1 *}$, Dean Quick $^{2}$, Jessica Hassall ${ }^{3}$, Hailey A. Park ${ }^{14}$ \\ 1 Queens University of Charlotte \\ 2 Levine Cancer Institute - Atrium Heath, Queens University of Charlotte \\ 3 Queens University of Charlotte \\ 4 Voices Together \\ *pasialiv@queens.edu
}

Received: 4 March 2019 Accepted: 19 June 2020 Published: 1 November 2020

Editor: Helen Brenda Oosthuizen Reviewers: Susanne Bauer, Jennifer Bibb

\begin{abstract}
Eating disorders are serious disturbances in eating habits, body image attitudes, and weight that affect overall well-being and can have life-threatening consequences. Participation in music therapy sessions may allow for healing of anxiety, self-worth, and body-image challenges that each person may face. In this manuscript we examined the music therapy literature pertaining to clinical work with persons who have eating disorders. We describe six techniques (clinical improvisation, song autobiography, song discussion, songwriting, music assisted relaxation/imagery, and Bonny Method of Guided Imagery and Music) and their reported uses in the literature. While the evidence supports that these techniques are effective, we acknowledge that what works in one context may not be culturally relevant or effective in another. The overview of the evidence in the literature corroborates how therapists who work with persons who have eating disorders tend to use music therapy techniques as pathways for contributing to sense of self. For each technique, we provide clinical examples with a strong element of the need to redevelop or discover identity.
\end{abstract}

Keywords: eating disorders, adolescent, music therapy, review, treatment

\section{Music Therapy Programming for Persons With Eating Disorders: A Review With Clinical Examples}

Eating disorders are serious disturbances in eating habits, body image attitudes, and weight that affect well-being and can have life-threatening consequences. They are often comorbid with other mental illnesses such as mood, anxiety, or personality disorders ( $5^{\text {th }}$ ed.; DSM-5; American Psychiatric Association, 2013). Treatment for persons with eating disorders occurs in inpatient or outpatient settings depending on the severity and chronicity of symptoms (Frisch, Franko, \& Herzog, 2006). Each person with an 
eating disorder will have a unique personal background, different trajectories of symptomatology, and distinct ways of coping. During music therapy sessions, participation in evidence-informed interventions may help each person better understand their eating disorder. Each person may have opportunities to: discover and learn more about themselves, identify feelings and emotions, enhance self-identity, and develop alternative coping strategies (Heiderscheit, 2009, 2016; Loth, 2002; McFerran, 2010; Trondalen, 2016). An evidence-informed approach to treatment planning entails examining the current literature in music therapy in order to better understand how to formulate session plans and develop therapeutic programming. The purpose of this paper is to provide information on how the health needs of persons with eating disorders can be addressed in music therapy by discussing the evidence in the literature regarding what works, to bring forth desirable outcomes.

This paper began as a class assignment (third and fourth authors) and evolved into brainstorming with a professional music therapist and clinical supervisor who has clinical experience working with persons with eating disorders (second author) and who added clinical examples. The project progressed into a faculty-student undergraduate research project (first and third authors) that evolved into this manuscript. Our manuscript reflects how we engaged in a collaborative effort to further understand music therapy as a viable therapeutic vehicle for people with eating disorders.

We structured the paper by discussing six therapeutic techniques mentioned in music therapy literature and seeking examples on how our consulting clinician (second author) has implemented each in his clinical practice. First, we explain each technique in a generic manner. Then, we continue with information we extracted by reviewing the literature (focusing on benefits, limitations, and specific uses of the technique). We end by providing a clinical example on how our consulting clinician (second author) has implemented the specific technique during clinical work conducted in an outpatient facility for girls and women with eating disorders. As authors we acknowledge that treatment programs include people of all genders. Thus, we encourage readers to view the clinical examples as suggestions and not step-by-step instructions on how to provide music-based experiences that are culturally relevant across different settings. The six therapeutic techniques and their reported uses in the literature that we discuss are: clinical improvisation, song autobiography, song discussion, songwriting, music assisted relaxation/imagery, and the Bonny Method of Guided Imagery and Music.

\section{Clinical Improvisation}

The specific ways music therapists use improvisation will vary based on health needs, clinical settings, professional training, and therapeutic method or approach. In the music therapy literature, Wigram (2004) defined clinical improvisation as the use of musical skills needed to engage in active music making within a therapeutic context and with a therapeutic intent. Similarly, Beer (2011) described improvisation in music therapy as any attempt during clinical practice to co-create music that varies on a continuum, ranging from structured and preplanned exercises to free and unrestricted improvisation. Given the range of active music making experiences that can "classify" as improvisation, this technique can be flexibly adapted to meet therapeutic needs.

As pointed out by McFerran, Baker, Kildea, Patton and Sawyer (2011), most case studies in the music therapy literature where improvisation is discussed as an intervention for people with eating disorders have been reported by therapists who use a psychodynamic theoretical framework. However, some authors report using more structured experiences such as drumming (e.g., Hilliard, 2001). Music therapists working with persons with eating disorders describe music improvisation as a clinical method that affords opportunities of exploration of deep feelings and self-expression (e.g., Heiderscheit, 2009; McFerran, 2010; McFerran \& Heiderscheit, 2016; Trondalen, 2011). Because some people with eating disorders may have perfectionistic tendencies, improvisation is a way to engage in an experience where there is no right or wrong and therefore bring forth feelings of empowerment (Heiderscheit, 2009; McFerran \& Hei- 
derscheit, 2016). Even though improvisation may feel uncomfortable for some people, over time it can allow space to explore and subsequently process different aspects of an eating disorder's causes and symptoms (Heiderscheit, 2009; Trondalen, 2016). People with eating disorders may express their unstable self-esteem during improvisation. Over time, the musical exploration of inner feelings may lead to an increased awareness of mind-body, even when a person has a disconnection between their emotions and their bodies due to an eating disorder (Trondalen, 2016).

Therapists who tend to use free-improvisation strategies in individual or group therapy may allow each person to freely improvise on whatever instrument they choose, because instrument choice may have a large impact on the person, as well as reveal clinical insights about their progress in rehabilitation (Bauer, 2010; Trondalen \& Skårderud, 2007). As Bauer (2010) indicated from her music therapy sessions, one person with bulimia nervosa "preferentially played [loud and harsh sounds] on the big tube xylophone or on the piano, [and] the therapist sensed a search for attention mixed with rage and desperation" (p. 1). The therapist interpreted that this person often chose large, bold instruments due to her desire to be recognizable. In music therapy sessions, other participants may also choose their instruments for projecting their needs and emotions. For example, as a way to introduce younger persons to, and engage them in, clinical improvisation, Sloboda (1995) asked them to select musical instruments to represent specific people, concrete themes or ideas.

In free improvisation, as the session participant and therapist create music together, the therapist may encourage each person to play according to however they feel. The therapist follows and attempts to match or contain how a person is playing, thus attuning to their feelings. Trondalen and Skårderud (2007) describe this process of "affect attunement" as "elucidat[ing] the sharing of inner feelings states," creating a way for the therapist to relate to the emotional state of the person they are improvising with (p. 100). When the therapist recognizes and emphasizes an individual's emotional expression through music, the person may feel noticed and real-an important feeling for someone who may have a fragile mental state. This affect attunement can also lead to "significant moments"-moments in the improvisational process that Trondalen (2003) describes as instances of "connectedness through musical sharing at a non-verbal level" (p. 6) and can both enhance the therapeutic relationship and increase a person's confidence (Lejonclau \& Trondalen, 2009).

Therapists need to be aware of how a person's music making during the improvisation may manifest symptoms of an eating disorder. Their improvisation may include a lack of structure, efforts to control the music making by allowing no spaces or 'rests', and rigidity of either imitating each nuance of the therapist's playing or playing in a disengaged manner (Robarts \& Sloboda, 1994). Robarts (1995) describes those polar opposite patterns of musical interaction (conforming and lacking spontaneity versus being rigid and controlling) as erected barriers to empathetically connecting with the therapist. Thus, gradually working towards empathetic musical connection and spontaneous self-expression is central to the therapeutic process.

After engaging a person with an eating disorder in free improvisation, the clinician may follow up with verbal processing of, or self-listening to, a recording of the improvisation. As described by Trondalen (2003), self-listening entails revisiting a recording of the music improvisation and pinpointing significant and meaningful moments. By identifying those moments together with a therapist, a person with an eating disorder may develop increased awareness of inner thoughts, feelings, and emotions (Trondalen, 2003). The concept of reconnecting with emotions, thoughts, and feelings is important for persons with eating disorders because as a person "attempts to control difficult emotions by controlling physical impulses and bodily needs via maladaptive eating behaviors" they may become "disengaged from their emotional state and sense of self" (Dokter, 1995; as cited in Boblin, 2008, p. 145). Verbal processing (rather than self-listening) or discussion of improvisations may also address disconnections between emotions and body image issues due to an eating disorder, particularly when identifying peak moments in improvisation. Those peak moments occur when there is a con- 
nection of the mind and body, a connection that can be verbally reflected upon afterwards (Heiderscheit, 2016; Lejonclau \& Trondalen, 2009; Trondalen, 2016).

A therapist's philosophical orientation and approach to clinical practice will influence how and in what ways self-listening or verbal reflection is implemented during a session. Therapists who use clinical improvisation with persons with eating disorders will need to focus on clinical musicianship, cultivating a strong ability to musically listen, empathize, and contain musical responses during sessions. They may also need to develop their clinical improvisation skills through additional training or supervision. The clinical example below reflects how a clinician, the second author, used improvisational role play in their practice.

\section{Clinical Example}

The second author used improvisational role playing with a group of four females, all with bulimia nervosa and an Axis II diagnosis of borderline personality disorder. The second author gave the group a worksheet prompting them to choose five parts of themselves individually to share with the group. There were no limitations as to what parts of the self the participants could choose. Examples given were "happiness", "anxiety", "compassion", "bulimia", and so forth. After writing these parts on small pieces of paper, the second author asked for a volunteer to share their roles first. The second author asked the participant who volunteered to share their roles first, to assign each of the "parts of their self" with group members and the music therapist. This person in the lead role role-played as their self. After assigning the roles, the group member in charge of assigning roles then assigned an instrument to each role and instructed each person how to embody their role musically. Once all group members had their playing style, the person leading the role-playing began playing their instrument and focusing on her interactions with opposing or supporting roles. The other group members joined in the improvisation in manners congruent with their embodied role, as assigned by the group member leading and composing the music (thus composing their "self" in musical form). Once the improvisation ended, the lead participant engaged in verbal processing regarding her musical interactions with the roles, and how that musical representation compared or differed with the way the roles organically occurred in her life. The improvisation functioned as a springboard, allowing her to identify and work through painful and non-constructive aspects of her identity.

Since control can be a defining struggle for those diagnosed with eating disorders, it is a common theme introduced in role-playing, as well as anxiety. This improvisational approach to role playing has allowed the adults in various groups that the second author facilitated, to experience concurring roles within the self in a nonverbal and accessible way. Moreover, it has opened discussion about the power of some roles over others in their lives and enabled them to experience these roles in ways they are unable to in non-experiential therapies. Participants were able to distance their self from the emotional processing and were instead instructed to listen to how the parts of their self interacted. A participant who experiences extreme anxiety might not fully understand how anxiety almost completely overpowers something positive like joy. When anxiety was assigned to a loudly played drum and joy to a soft triangle rhythm, the difference became clearer. Vulnerability became less frightening because emotions were shaped into something tangible and less ambiguous. When the participants were introduced to their self in a musical way, they typically were able to discuss more difficult emotions with the group. The music represented each part of the participant's self in a concrete way. Specifically, the emotions were represented in a way that allowed the participants to talk about them non-emotionally. This process also supported the participants' need for control and validation.

\section{Song Autobiography}

This music therapy technique (also known as music life review or song biography) entails the therapist and the client identifying important songs that reflect a person's life 
journey. Those songs can be associated with life events, celebrations, or reflections upon personal situations a client is experiencing. The selected songs can then be sung or performed with clients. Alternatively, the therapist can develop a narrative and use recorded versions of the songs, which can then be compiled into a collection that the client can access at any time (Grocke \& Wigram, 2007).

Music therapists describe using song autobiography in order to help people with eating disorders establish their sense of self through a musical presentation (Amir, 2012; Heiderscheit, 2009; Parente, 1989). When describing the intervention of "song autobiographies" Heiderscheit (2009) stated that during individual sessions the client would think of specific moments in their lifetime and then select songs to fit those moments-pinpointing specific life moments before letting music come to mind. The aforementioned authors described how the independence given to the client for selecting music can be beneficial in helping them to become more self-aware about their own identities. The songs selected can reflect their sense of self, personality, desires, or dreams. Many persons with eating disorders have songs in which they identify to the lyrics or the emotional congruence of the music. These songs can help each person feel their emotions are expressed or validated. Music therapists using song autobiography can encourage clients to dig into a song's lyrics to find a meaning that may trigger the client to respond (Heiderscheit, 2016). Thus, song autobiography may transition to song discussion. Moreover, creating a musical presentation through song autobiography may also be beneficial in different ways when it allows clients an opportunity to choose their own songs, present them to others, and explain (if desired) their reasoning behind choosing the songs (Amir, 2012; Heiderscheit, 2009; Parente, 1989).

Amir (2012) described the musical presentation of song autobiography as a "personal and meaningful musical collage, which enables [the person] to create and share [their] personal and musical identity" (p. 176). In the study she conducted, the participants each took turns creating and presenting a personal $\mathrm{CD}$, to which they burned songs according to significance, memory, or importance. For many of the participants in the study, their personal collection consisted of many childhood songs such as lullabies, sing-alongs, or first songs learned on an instrument. Some participants' presentations were more mellow or melancholic, whereas others selected happier and more upbeat music. By listening to and observing the various styles and characteristics of the music, the participants learned more about each other and also became more aware of their own identities (Amir, 2012).

The above uses of song autobiography are closely related to narrative therapy. Narrative therapy uses the idea that the client's perceptions of themselves and the world relate to stories, which eventually become their permanent truth (Augusta-Scott \& Brown, 2007). Therapists help each person to take a step back and see a broader perspective of their life. Song autobiography then becomes a pathway for addressing their difficulties by telling an alternative story that includes a comprehensive narrative of their personal identity. This therapeutic process can link together songs and stories. In a group setting, each person can listen to each other's "songscaped" life stories, find connections and similarities. The above process may increase empathy and awareness (Heiderscheit, 2016).

\section{Clinical Example}

The most powerful work the second author has facilitated for persons with eating disorders is the autobiography in song project. (See Appendix 1 for a formatted example of a worksheet the second author has handed to clients.) The second author had therapists anecdotally tell him that their clients with eating disorders shared more in their song autobiography than they did in their narrative session. The second author believes the music itself helped in that deeper divulgence of history. Adolescent participants were hardly ever hesitant or resistant to this project, and because of this enthusiasm, they seemed more comfortable sharing the truth about their individual situations. Sharing music, particularly with the ease of access and prevalence of online streaming, 
is something adolescents are already doing. Music is part of their identity (see McFerran, 2011) and the song autobiography was a process that appeared to support them in exploring their personal challenges and individual resources. It is the second author's opinion, based on experiences with those he worked with, that reflecting upon identity and how music shapes parts of the self deepens the person's understanding of their development. The song autobiography creates powerful visuals for a person to re-experience both positive and negative life events. Those visuals can bring forth insights and reflections that may have been suppressed or dulled because of the eating disorder.

The process of creating the autobiography is powerful but what the second author found to be most impactful was having the participants individually present their completed project to the treatment community of the facility (staff and peers). This process entails working with each person individually to find which parts of live or recorded music they can use during a presentation. The music is then used either as a preface, or after their explanation of why they chose the music for respective parts and people in their lives. During the presentation, the second author sat beside the person and offered support while they presented, as well as asked for clarification or probed for more information. After all of the music was shared, each person observing was invited to share something positive and encouraging about the person presenting their life journey. The second author offered the opportunity for each person to do the presentation on their own or to do it with his support; the overwhelming response was to choose the support because sharing the song autobiography brought forth strong emotions. Oftentimes, the presentation was exploratory narrative, revealing information about each person that was shared for the first time (information peers and support network did not know). In addition to providing emotional support, sitting beside each person also served the function of controlling and sequencing the presentation of the music. The speakers were located behind the person; thus, the music was projecting from the same physical location as the voice of the person. Sharing the song autobiography included elements of song discussion, which is the technique presented next.

\section{Song Discussion}

According to Gardstrom and Hiller (2010), song discussion in music therapy can combine both an exploration of the lyrics as well as the musical elements of the song such as the tempo, harmony, accompaniment, and musical interpretation. Gardstrom and Hiller practice song discussion as a technique where the therapist preselects a song to discuss with clients by carefully considering psychological processes (such as projection and identification) and specific attributes of the person, lyrics, musical accompaniment, stage of treatment, and personal choice. They acknowledge that in the music therapy literature, song discussion may also occur in different ways, such as a person presenting a song for self-expression or analyzing lyrics of a song improvised or precomposed by a client. The various ways song discussion can be implemented in music therapy sessions also allow for flexible adaptation to meet the needs of persons with eating disorders.

Similar to the recommendations of Gardstrom and Hiller (2010), clinicians who use song discussion with people who have eating disorders also emphasize looking into the lyrics as well as other musical elements such as instrumentation, rhythm, and tonality. These elements of a song all provide projections into a person's story (Heiderscheit, 2009; Punch, 2016). Song discussion does not encompass as much freedom of expression as improvisation, yet in a similar manner it may legitimize feelings and allow each person to put into words topics they may have previously been unable to express. Particularly with adolescents, song discussion may allow exploration of their identity while challenging the thoughts and feelings evoked by the eating disorder (McFerran, Baker, Patton, \& Sawyer, 2006). Song choice is important and can be used to elicit emotional responses typically repressed by the eating disorder. If a song selected by the therapist (or by a group member) is unfamiliar to an individual, they will need to engage in active music listening. Active music listening to an unfamiliar song requires 
a person to completely pay attention and focus on the different musical elements of a song in order to identify what those are. This concentration can help a person by increasing their awareness and engagement in therapy sessions (Punch, 2016).

Music therapists using song discussion have asked people with eating disorders to self-select songs that explain their life story, in order to help them feel their emotions are valid (Heiderscheit, 2009,, 2016; Punch, 2016). The lyrics of songs selected by each person may stimulate discussion because they give the music therapist insight into a person's inner world (Heiderscheit, 2009). Other therapists preselect the songs to explore during a session, in order to preplan a discussion pathway. For example, Hillard (2001) discussed how singing Jackson Browne's "Running on Empty" with clients functioned as a way to "give a voice to the feelings they had of giving too much of themselves away" (p. 111).

The verbalization and expression of feelings evoked during song discussion is also one way to reduce anxiety-a common area of need for people with eating disorders because of high incidences of continued cumulative stress or traumatic past experiences (Bauer, 2010; Heiderscheit, 2009). The distress of constantly repressing painful memories or feeling unworthy can bring about many unhealthy coping mechanisms, such as eating disorders. Even though it may appear as counterintuitive, the rehabilitation environment can even increase stress and anxiety when disordered eating is not allowed to continue. Thus, another treatment goal is coping with this anxiety or stress in a healthy manner, rather than a harmful one (Justice, 1994).

As an expressive treatment modality, song discussion may be scheduled after meals as a way to connect to difficult emotions that arise after eating. Song discussion may allow an indirect pathway to identifying and projecting difficult emotions, thoughts, fears, and anxieties. Bibb, Castle, and McFerran (2019) measured post-meal-related anxiety for people with eating disorders. During group therapy sessions, the music therapist encouraged participants to discuss preferred musical genres and songs, including the specific meanings of lyrics. Emerging discussion themes included issues pertaining to recovery and body image. The study outcomes indicated significant reduction in anxiety. Their findings corroborated the results of earlier studies (see Bibb, Castle, \& Newton, 2015, 2016).

When used skillfully, song discussion may address what each person might be seeking through symbolism, vulnerability, constant and inevitable change, and the desire for meaning. Tact and confidence are needed when navigating the waters of self-exploration with groups and individuals through song discussion. Music therapists, therefore, must fully understand, not only the music being selected by each person (or by the therapist), but also, to some degree, the lives of the people and their specific vulnerabilities. Reflecting upon our clinical practice and experiences as authors of this manuscript, we believe that the answer to this question of meaning is not always apparent in the moment. The concerns and need for emotional exploration, including an understanding of personal mental health, are usually rooted in the things that come up in the moment as a person engages in song discussion. Typically, it is the need to understand something in the past and the reactions in the moment that are hindering the exploration process. Oftentimes this hindering can be due to vulnerability, and therein a music therapy intervention, such as song discussion, can facilitate exploration. When using song discussion, particularly with vulnerable persons, a therapist must be prepared for full exploration and discussion facilitation. There can be hesitation on the part of young therapists to lead song discussion that may stem from not wanting to sway out of or blur the lines of scope of practice, or sometimes with seasoned professionals with new groups when someone says something unexpected (Chen \& Rybak, 2018). Thus, therapists using song discussion need to hone their micro-counseling and session leadership skills. 


\section{Clinical Example}

It has been the second author's experience that when using song discussion with people who have eating disorder, themes of trauma, personality, body image, empowerment, and self-esteem seem to recur. Song discussion seems to be most popular among the adolescent age group. Typical song discussion groups the second author conducted were one hour to 90 minutes in length. The longer session length was because the group discussion often led to rewriting the song. Songwriting in conjunction with song discussion has not only been seemingly enjoyable, particularly for adolescents with eating disorders, but also a way for the group to express their ideas and gain positive control over media influences in their life. This combination served as a connecting point and most times provided the group with opportunities for bonding and strengthening cohesion. Subsequently, this cohesion frequently led to improved altruism among participants, even outside of music therapy groups. Participants supported each other more at difficult meals and in different therapy groups.

As a way to introduce song discussion, the second author invited group participants to use the "Sound Relationships Nutritional Label" (Boston Public Health Commission, 2009). This tool supports analysis of healthy relationship ingredients (e.g., respect, trust, fun, equality) versus unhealthy relationship ingredients (drama, possession, disrespect, manipulation) reflected in songs. This less direct way of introducing discussion lowered defenses and made participation more accessible. The second author used this tool as a springboard for discussion with songs that either he or the group participants selected. During the music therapy sessions, the second author used either recorded or live versions of the songs, based on preferences and the outcomes being addressed. Song discussion often transitioned to songwriting by rewriting some of the unhealthy relationship elements presented in the song lyrics, to represent their opposite, more positive relationship elements. Transition from song discussion to rewriting of lyrics made sessions more cohesive and increased interactions and contributions from all participants.

\section{Songwriting}

Therapeutic songwriting entails creating, notating, or recording lyrics and music during a music therapy session. Songwriting involving songs created collaboratively with clients during sessions is a broad practice that may range from fill-in-the-blank techniques, writing lyrics that fit a preexisting song, to improvising lyrics, to writing both original lyrics and music (Baker, 2015). Music therapists use songs to enhance choice and decision making, develop self-concept and self-esteem, and create a way to share personal stories or externalize thoughts, ideas, and feelings (Baker, Wigram, Stott, \& McFerran, 2008). Tamplin (2006) provided a list of therapeutic techniques used by therapists for developing lyrics during sessions that includes: engaging in vocal improvisation, using client written poetry or precomposed lyrics, brainstorming and reframing ideas, selecting topics or specific words from a list, using probing or open ended questions, using song parody by changing lyrics to pre-existing songs, word substitution, and bringing together various lyrics/phrases from existing songs. Those lyrics can be piggybacked by using an existing melody, or all content of the song can be original, developed using spontaneous improvisation or a step-by-step process to solidify original ideas into a written or recorded product (see Stewart \& McAplin, 2016).

In the music therapy literature, songwriting is used most often with persons who have a general mental health/psychiatric diagnosis or with those who have experienced abuse/trauma (Stewart \& McAplin, 2016). For persons with eating disorders, songwriting is helpful during individual and group sessions. Songwriting may create a pathway for sharing personal information, reaffirming feelings, and finding validation (Heiderscheit, 2009; Punch, 2016; McFerran et al., 2006; McFerran \& Heiderscheit, 2016). Some therapists may provide prompts and allow each person (or the group) to engage in a collaborative process for writing lyrics (Heiderscheit, 2009; Siegel, 2007). The participants and music therapists can create their own original music or can use 
an existing prewritten tune for their lyrics (McFerran \& Heiderscheit, 2016). Some song topics may include personal histories of their eating disorder, descriptions of the process of stepping away from their eating disorder, and how they are coping with their treatment (Heiderscheit, 2009; Trondalen, 2016). Moreover, music therapists can provide guidance for creating songs about what healthy, healed bodies should be like, and the eating disorder recovery process. The creative process of composing songs allows for the group members to develop rapport with each other and discuss difficult concepts and feelings (Heiderscheit, 2009; Punch, 2016).

McFerran, Baker, Kildea, Patton and Sawyer $(2008,2011)$ analyzed lyrics of songs composed by young women with eating disorders and found that issues of identity as well as relationship dynamics within the family were the most frequently identified topics. Moreover, in their songs, adolescents may reflect on who they were, compare themselves to their peers, and explore themes of independence and self-limitations (McFerran, Baker, Patton, and Sawyer, 2006). McFerran et al. (2006) found that with songwriting, people with eating disorders may attempt to reestablish their identity through positive self-talk and may develop increased self-awareness over time. When people with eating disorders can have a sense of self-honesty they may no longer put on a façade for others or try to manage unhealthy emotions by controlling eating habits (McFerran et al., 2006).

To sum up, by engaging in song creation, each person can find a pathway for constructing a tangible record representing their personal journey. Songwriting provides an outlet through which people with eating disorders may be able to explore their self. Music therapists need to familiarize themselves with various genres and learn to experiment with different chord progressions. Experience with electronic and recording equipment is also useful because it allows the therapist to record songs created during music therapy sessions.

\section{Clinical Example}

Songwriting is a typical extension of lyric analysis/song discussion, but when isolated and used over the course of several sessions it can be clinically effective, particularly for adolescents with eating disorders. In his work with persons who have eating disorders, the second author has used songwriting as means of transferring dream journals, poetry written in the past, and newly written other forms of prose, to musical form. This use of prose and poetry has allowed people with eating disorders to explore and revisit themes in their psychological development, relationships, and development of eating disorder behavior. The creation of the music seemed to be the biggest barrier to active engagement in the therapeutic process for most group members, because many persons we music therapists serve are not trained musicians. The use of electronic instruments made the process of music composition easier and less intimidating. By eliminating the pressure arising from not knowing how to play an instrument, people are more likely to explore sounds to capture the aesthetic of their written work. The second author used a fluid session structure that included conducting a check-in in the beginning of the session and allowing time for verbal processing at the end. Verbal processing was supported throughout the session as needed. Typically, he allowed four to six sessions for the group and/or individuals to create one song, and found that establishing a due date for the creation was helpful in managing perfectionistic behavior. Other than music composition, addressing perfectionism was the next biggest challenge and in addition to the established due date, he only allowed participants to use pens and/or permanent markers when creating/editing their creative work. A pen cannot be erased, only struck-through, so participants saw the progress of their creativity and thoughts. It is important for persons with eating disorders to challenge perfectionism because the eating disorder "voice" can get louder with self-deprecation when "weakness" is present. Any imperfection can be perceived as weakness and may potentially become justification for self-injurious behavior, including purging and restricting caloric intake. 


\section{Music-Assisted Relaxation \& Imagery}

Music-assisted (or music-reinforced) relaxation is a technique where a therapist uses music to help the client lower stress and anxiety levels, while directing their "attention away from obsessive or intrusive thoughts." It employs techniques such as "stretching, deep breathing, progressive muscle relaxation, and focused (directed) imagery" (Justice, 1994, p. 106). Directed imagery techniques involve asking a person to relax and imagine a comfortable place, which can be either real or imaginary. In the music therapy literature, Grocke and Wigram (2007) provided specific guidelines on how clinicians can adapt receptive methods such as music-assisted relaxation in clinical practice, while considering environmental factors, specific ages and diagnoses, and appropriate musical material.

According to Justice (1994), these methods of relaxation give persons with eating disorders "greater awareness of their physical reactions to stress and emotions as well as several options for dealing with anxiety as it arises" (p. 107). Heiderscheit (2009), suggested that a music therapist may use live active music making or recorded music. For live music making, a music therapist may play a relaxing melodic instrument like guitar or flute while the client plays a rhythm instrument to elicit a relaxed state. For recorded music, Heiderscheit recommends selections with embedded nature sounds like rain or running water for calming purposes. Overall, the type of music selected, whether live or recorded, depends on what makes each person the calmest and reduces stress.

The use of music-assisted relaxation for persons with eating disorders needs to be introduced cautiously. Since a large number of persons with eating disorders may have a history of trauma (see Trottier \& MacDonald, 2017) music-assisted relaxation can be terrifying for some. Because of the intimate nature of this technique, people with trauma-heavy backgrounds may avoid or request not to participate in music-assisted relaxation either due to the inability to lie down in a room full of people, the hesitation to close the eyes because of inhibitions in trust, or the avoidance of anything involving imagery due to a lack of control. Thus, a clinician needs to introduce musicassisted relaxation after careful consideration of the clinical history, and direct collaborative consultation dialogue with each person. Also, a therapist may need to consider, as Tileston (2013) recommends, using more general language, rather than mentioning specific body parts.

\section{Clinical Example}

The second author found the structure and predictability of progressive muscle relaxation allowed him to introduce this technique in a more concrete manner. The stepby-step directions of which general area of the body to contract and then relax seemed to allow fewer wandering thoughts, hence decreased the opportunity of intrusive negative thoughts, beliefs and actions in relation to their bodies. Particularly with adolescent groups, the second author noticed improvements in self-reported comfort level with body image and awareness. Within the structure of music-assisted progressive muscle relaxation, participants were able to focus on parts of their bodies that, as a result of the eating disorder, they may have been triggered to think about in negative ways. The music and the relaxation technique provided a comfortable and supportive space that allowed participants to connect their body experience with their mind. This technique provided the means to open discussion on the issue of body image and particularly the actions associated with specific beliefs about how they saw themselves or interpreted the way they looked. Thus, the second author sometimes used music-assisted relaxation as a way to transition into a more verbal-driven therapy session. In order to deliver verbal instructions, the second author preferred using live music by providing a repeated chord structure with the guitar. The second author has also sometimes used an idiopan (steel tongue drum) because it allowed him the flexibility of multiple tunings as well as adding melodic elements to the live music. 


\section{Bonny Method of Guided Imagery and Music}

The Bonny Method of Guided Imagery and Music (GIM) is a psychotherapeutic treatment approach that requires advanced training/certification and targets deep exploration of a person's emotions. With GIM, clients access unconscious information via self-generated images through the use of music and verbal communication. The aim is to help each person gain insight, discover their own solutions to their problems, and feel empowered. Typically, a GIM session has four phases: allowing deep relaxation; transitioning into a state of altered consciousness; listening to music selections while experiencing imagery, sensations, or both; and sharing those experiences with the therapist who functions as a guide during the session. Music listening programs have originally been designed by Helen Bonny and expanded or modified by other GIM therapists (Goldberg \& Dimiceli-Mitran, 2010).

In the music therapy literature, GIM is often used to find and understand the underlying origins and issues of an eating disorder. GIM treatment is offered either in one-on-one or group sessions. Insurance billing and setting requirements may necessitate shortening and adapting GIM sessions (Heiderscheit, 2015). Age may also play a role in adapting session length. Adolescents may need a concrete relaxation induction that may be perceived as "safer", with musical selections being shorter in the beginning then gradually increasing in complexity (Papanikolaou, 2015).

A group GIM session might be beneficial when participants all have similar treatment goals (Heiderscheit, 2009, 2016). Group therapy adaptations in the literature included using stories or poems as prompts leading or supporting imagery (Justice, 1994), or music improvised by the therapist (Noer, 2015). During inductions, therapists may use movement, focused breathing, or stretching. Barmore (2017) found that music therapists have adopted recommendations in the literature to use general language to describe locations of the body, rather than specific body parts during GIM induction exercises.

One-on-one sessions are more conducive for in-depth GIM. Based on the literature, GIM can be a way for people with eating disorders to work through the trauma by re-experiencing emotions related to body image, trauma, and anxiety, and exploring them through symbolism and imagery. Because none of the authors holds advanced certification and training in GIM, we are using a clinical example we obtained from the literature.

\section{Clinical Example}

Heiderscheit (2016) explored a clinical case study using GIM with one client who had low self-esteem. During the different sessions, the client became aware that she had to protect herself when she was younger because nobody looked out for her. She had difficulty feeling safe and comfortable because of the trauma she endured as a young girl. Moreover, she felt ashamed of the abuse that she had endured and believed she did not deserve people's attention. She felt emotionally stuck in the past because of the trauma, and that her eating disorder was a distraction. Exploring the aforementioned clinical needs during GIM sessions allowed the client to release herself of the emotional load she had been carrying (Heiderscheit, 2016).

\section{Conclusion}

In this manuscript we examined the music therapy literature pertaining to clinical work with persons who have eating disorders. We described six techniques (clinical improvisation, song autobiography, song discussion, songwriting, music assisted relaxation/imagery, and the Bonny Method of Guided Imagery and Music) and their reported uses in the literature. While the evidence supports that these techniques are effective, we acknowledge that what works in one context may not be appropriate or effective in another. The clinical examples provided by the second author offer suggestions that we hope will be informative for the readers of this manuscript. 
A strong element in the clinical examples provided is the need to redevelop or rediscover identity. The overview of the evidence in the literature also corroborated how therapists who work with persons who have eating disorders tend to use music therapy techniques as pathways for contributing to sense of self and identity. A close look into how music functions within the therapeutic techniques each therapist selects also indicates a need to search for meaning and emotional healing. For persons with eating disorders, emotional healing can be a catalyst in facilitating physical healing, and thus, participation in music therapy sessions may affect overall health. Each clinical technique explored in this manuscript affords unique opportunities for each person to be receptive to learning more about themselves, and to share their feelings and stories. When the connection of the heart, mind and body becomes the focus of therapeutic interventions, music therapy sessions can function as the container where feelings, bodyimage, anxiety, and self-worth/self-esteem issues can be addressed and explored.

\section{About the authors}

Varvara Pasiali, PhD, MT-BC, is an associate professor of music therapy. Dean Quick, MT-BC, is a music therapist at Levine Cancer Institute - Atrium Health, and supervised students at Queens University of Charlotte. Jessica Hassall, MT-BC, and Hailey Park, MT-BC, contributed to this article while studying music therapy at Queens University of Charlotte. Correspondence concerning this article should be addressed to Varvara Pasiali, PhD., MT-BC, Associate Professor of Music Therapy, Queens University of Charlotte, 1900 Selwyn Ave., Charlotte NC 28274. Contact: office 704-688-2720; email pasialiv@queens.edu

\section{References}

American Psychiatric Association. (2013). Diagnostic and statistical manual of mental disorders (5th ed.). https://doi.org/10.1176/appi.books.9780890425596.

Amir, D. (2012). "My music is me": Musical presentation as a way of forming and sharing identity in music therapy group. Nordic Journal of Music Therapy, 21(2), 176-193, https://doi.org/10.1080/08098131.2011.571279.

Augusta-Scott, T., \& Brown, C. (2007). Narrative therapy: Making meaning, making lives. SAGE Publications.

Baker, F. A. (2015). Therapeutic songwriting: Developments in theory, methods, and practice. Palgrave Macmillan.

Baker, F., Wigram, T., Stott, D., \& McFerran, K. (2008). Therapeutic songwriting in music therapy. Part I: Who are the therapists, who are the clients, and why is songwriting used? Nordic Journal of Music Therapy, 17(2), 105-123, https://doi.org/10.1080/ 08098130809478203.

Barmore, L. (2017). The Bonny Method of Guided Imagery and Music (GIM) and eating disorders: Learning from therapists, trainer, and client experiences (Unpublished saster's thesis). Appalachian State University. https://libres.uncg.edu/ir/asu/f/ Barmore,\%20L_2017\%20Thesis.pdf.

Bauer, S. (2010). Music therapy and eating disorders - A single case study about the sound of human needs. Voices: A World Forum for Music Therapy, 10(2), https://doi.org/10.15845/ voices.v10i2.258.

Beer, L. (2011). A model for clinical decision making in music therapy: Planning and implementing improvisational experiences. Music Therapy Perspectives, 29(2), 117-125, https://doi.org/10.1093/mtp/29.2.117.

Bibb, J., Castle, D., \& Newton, R. (2015). The role of music therapy in reducing post meal related anxiety for patients with anorexia nervosa. Journal of Eating Disorders, 3, 50, https://doi.org/10.1186/s40337-015-0088-5. 
Bibb, J., Castle, D., \& Newton, R. (2016). 'Circuit breaking' the anxiety: Experiences of group music therapy during supported post-meal time for adults with anorexia nervosa. The Australian Journal of Music Therapy, 27, 1-11, https://www.austmta.org.au/journal/ article/\%E2\%80\%98circuit-breaking\%E2\%80\%99-anxiety-experiences-group-music-therapyduring-supported-post.

Bibb, J., Castle, D., \& McFerran, K. S. (2019). Reducing anxiety through music therapy at an outpatient eating disorder recovery service. Journal of Creativity in Mental Health, 14(3), 306-314, https://doi.org/10.1080/15401383.2019.1595804.

Boblin, M. (2008). Music therapy in the treatment of eating disorders. In S. L. Brooks (Ed.), The Creative Therapies and Eating Disorders (pp. 142-158). Charles C. Thomas.

Boston Public Health Commission. (2009). https://www.bphc.org/whatwedo/violenceprevention/start-strong/Pages/Resources.aspx.

Chen, M-W., \& Rybak, C. (2018). Group leadership skills. Interpersonal processes in group counseling and therapy. SAGE Publications.

Frisch, M. J., Franko, D. L., \& Herzog, D. B. (2006). Arts-based therapies in the treatment of eating disorders. Eating Disorders: The Journal of Treatment \& Prevention, 4, 131-142, https://doi.org/10.1080/10640260500403857.

Gardstrom, S. C., \& Hiller, J. (2010). Song discussion as music psychotherapy. Music Therapy Perspectives, 28(2), 147-156, https://doi.org/10.1093/mtp/28.2.147.

Goldberg, F. S., \& Dimiceli-Mitran, L. (2010). The central tenets of GIM: Consciousness and the integration of psychotherapy and spirituality. Voices: A World Forum for Music Therapy, 10(3), https://doi.org/10.15845/voices.v10i3.438.

Grocke, D., \& Wigram, T. (2007). Receptive methods in music therapy: Techniques and clinical applications for music therapy clinicians, educators and students. Jessica Kingsley Publishers.

Heiderscheit, A. (Host). (2009, August). Music therapy and eating disorders [Audio podcast episode]. In AMTA-Pro Podcast Series. http://amtapro.musictherapy.org/?p = 252

Heiderscheit, A. (2015). Guided Imagery and Music in the therapeutic hour: A case illustration of an adult client in eating disorder treatment. In D. Grocke \& T. Moe (Eds.), Guided imagery \& music (GIM) and music imagery methods for individual and group therapy (pp. 99-107). Jessica Kingsley Publishers.

Heiderscheit, A. (2016). The Bonny Method of Guided Imagery and Music in eating disorder treatment. In Creative arts therapies and clients with eating disorders (pp. 121-140). Jessica Kingsley Publishers.

Hilliard, R. E. (2001). The use of cognitive-behavioral music therapy in the treatment of women with eating disorders. Music Therapy Perspectives, 19(2), 109-113, https://doi.org/ 10.1093/mtp/19.2.109.

Justice, R. W. (1994). Music therapy interventions for people with eating disorders in an inpatient setting. Music Therapy Perspectives, 12(2), 104-110, https://doi.org/10.1093/mtp/ 12.2.104.

Lejonclou, A., \& Trondalen, G. (2009). "I've started to move into my own body": Music therapy with women suffering from eating disorders. Nordic Journal of Music Therapy, 18(1), 79-92, https://doi.org/10.1080/08098130802610924.

Loth, H. (2002). 'There's no getting away from anything in here": A music therapy group within an inpatient programme for adults with eating disorders. In A. Davies \& E. Richards (Eds.), Music therapy and group work: Sound company (pp. 90-104). Jessica Kingsley Publishers.

McFerran, K. (2010). Adolescents, music and music therapy: Methods and techniques for clinicians, educators and students. Jessica Kingsley Publishers.

McFerran, K. (2011). Music and adolescents. In N. S. Rickard \& K. McFerran (Eds.), Music and adolescents (pp. 97-108). Nova Science Publishers.

McFerran, K., Baker, F., Kildea, C., Patton, G., \& Sawyer, S. (2008). Avoiding conflict: What do adolescents with disordered eating say about their mothers in music therapy. British Journal of Music Therapy, 22(1), 16-23, https://doi.org/10.1177/135945750802200103. 
McFerran, K., Baker, F., Kildea, C., Patton, G., \& Sawyer, S. (2011). What's in the lyrics? A discussion paper describing the complexities of systematically analysing lyrics composed in music therapy. Canadian Journal of Music Therapy, 17(1), 34-54.

McFerran, K., Baker, F., Patton, G., \& Sawyer, S. (2006). A retrospective lyrical analysis of songs written by adolescents with anorexia nervosa. European Eating Disorders Review, 14(6), 397-403, https://doi.org/10.1002/erv.746.

McFerran, K. S., \& Heiderscheit, A. (2016). A multi-theoretical approach for music therapy in eating disorder treatment. In A. Heiderscheit (Ed.), Creative arts therapies and clients with eating disorders (pp. 49-69). Jessica Kingsley Publishers.

Noer, M. L. (2015). Breathing space in music: Guided imagery and music for adolescents with eating disorders in a family-focused program. In D. Grocke \& T. Moe (Eds.), Guided imagery \& music (GIM) and music imagery methods for individual and group therapy (pp. 71-85). Jessica Kingsley Publishers.

Papanikolaou, E. (2015). Short guided imagery and music (GIM) sessions in the treatment of adolescents with eating disorders. In D. Grocke \& T. Moe (Eds.), Guided imagery \& music (GIM) and music imagery methods for individual and group therapy (pp. 63-72). Jessica Kingsley Publishers.

Parente, A. B. (1989). Feeding the hungry soul: Music as a therapeutic modality in the treatment of anorexia nervosa. Music Therapy Perspectives, 6(1), 44-48, https://doi.org/ 10.1093/mtp/6.1.44.

Punch, S. (2016). Resilience-based music therapy in the treatment of adolescents with eating disorders. In A. Heiderscheit (Ed.), Creative arts therapies and clients with eating disorders (pp. 71-97). Jessica Kingsley Publishers.

Robarts, J. (1995). Towards autonomy and a sense of self. Music therapy and the individuation process in relation to children and adolescents with early onset anorexia nervosa. In D. Dokter (Ed.), Art therapies and clients with eating disorders (pp. 229-246). Jessica Kingsley.

Robarts, J. Z., \& Sloboda, A. (1994). Perspectives on music therapy with people suffering from anorexia nervosa. Journal of British Music Therapy, 8(1), 7-14.

Siegel, S. (2007). Music therapy practice for clients with eating disorders. In B. J. Crowe \& C. Colwell (Eds.), Effective clinical practice in music therapy: Music therapy for children, adolescents, and adults with mental disorders (pp. 149-164). American Music Therapy Association.

Sloboda, A. (1995). Individual music therapy with anorexic and bulimic patients. In D. Dokter (Ed.), Art therapies and clients with eating disorders (pp. 247-261). Jessica Kingsley Publishers.

Stewart, R., \& McAlpin, E. (2016). Prominent elements in songwriting for emotional expression: An integrative review of literature. Music Therapy Perspectives, 34(2), 184-190, https://doi.org/10.1093/mtp/miv011.

Tamplin, J. (2006). Song collage technique: A new approach to songwriting. Nordic Journal of Music Therapy, 15(2), 177-190, https://doi.org/10.1080/08098130609478164.

Tileston, P. (2013). Adults and adolescents with eating disorders. In L. Eyre (Ed.), Guidelines for music therapy practice in mental health (pp. 402-448). Barcelona Publishers.

Trondalen, G. (2003). "Self-listening" in music therapy with a young woman suffering from anorexia nervosa. Nordic Journal of Music Therapy, 12(1), 3-17, https://doi.org/10.1080/ 08098130309478069.

Trondalen, G. (2011). Music is about feelings: Music therapy with a young man suffering from anorexia nervosa. In A. N. Meadows (Ed.), Developments in Music Therapy Practice (pp. 434-452). Barcelona Publishers.

Trondalen, G. (2016). Expressive and receptive music therapy in eating disorder treatment. In A. Heiderscheit (Ed.), Creative arts therapies and clients with eating disorders (pp. 99-114). Jessica Kingsley Publishers. 
Trondalen, G., \& Skårderud, F. (2007). Playing with affects...and the importance of "affect attunement". Nordic Journal of Music Therapy, 16(2), 100-111, https://doi.org/10.1080/ 08098130709478180.

Trottier, K., \& MacDonald, D. E. (2017). Update on psychological trauma, other severe adverse experiences and eating disorders: State of the research and future research directions.

Current Psychiatry Reports, 19, 45, https://doi.org/10.1007/s11920-017-0806-6.

Wigram, T. (2004). Improvisation: Methods and techniques for music therapy clinicians, educators, and students. Jessica Kingsley.

\section{Appendix}

\section{Autobiography in Song example format}

This self-explorative project melds lyric analysis, journaling, and visual arts techniques. This project is an opportunity for you to explore your past and present self through examining the music that has been with you throughout your life. The lyrics of the songs you choose for this project should be the driving force behind selecting the music to represent each section of this assignment.

1. Stages of your life

a. Adolescents

i. Divide your life into 3 years stages and choose a song to represent each stage.

b. Adults

i. Divide your life into 5 years stages and choose a song to represent each stage.

2. Support Persons

a. Choose 3 people in your life who provide you with emotional support and find a song to represent each of these 3 people.

3. Eating Disorder

a. Choose a song to represent your eating disorder. Maybe the song is representative of how the eating disorder has affected you ... maybe it's the way you feel about your eating disorder. Maybe it personifies your eating disorder.

4. Recovery

a. Choose a song to represent your recovery. The lyrics of this song should convey your vision of recovery.

5. Album Artwork

a. Using any visual art medium, design an album cover to represent all the pieces of your life, either represented or not in the songs used. 